\title{
Living wills can help doctors and patients talk about dying
}

\author{
They can open the door to a positive, caring approach to death
}

Linda Emanuel
Northwestern University
Department of General
Internal Medicine
680 N Lakeshore Dr
Chicago, IL 60611
1-emanuel@
northwestern.edu
Competing interests:
None declared
This editorial was
published in BMJ
2000;320:1618-1619

2000;320:1618-1619
Many people are unaware of living wills but are highly interested once they hear about them. Schiff et al described finding that elderly inpatients are confused by the term "living will," but most would welcome the chance to discuss issues about facing the end of life, and many would want to limit their health care if they were terminally ill. ${ }^{1}$ In an assessment of the understanding of living wills in the United States some time ago, a similar state of affairs was found. ${ }^{2}$ This juxtaposition of ignorance and interest raises an important question: What is this apparent appetite to discuss and prepare for dying?

When lawyer Louis Kutner proposed the notion of a living will in 1969, he was responding to the fear that technology was driving physicians to impose lifesustaining treatment on patients who might not want it. The living will was seen as a simple device to allow patients to say no, even if they were too ill to communicate. The first living wills used phrases such as avoiding "heroic treatment" in the face of a "hopeless prognosis," and states passed legislation to give legal sanction to physicians honoring such directives throughout the United States. But physicians found difficulty translating these dispositions into specific treatment choices. A new wave of work began: the development of validated worksheets. ${ }^{3}$

It is difficult to turn subjective phenomena such as a person's values and goals for care in hypothetical scenarios into objective criteria. But psychometricians have set out a series of standards for the valid framing of topics and for eliciting and recording opinions, wishes, and reasoning. ${ }^{4}$ So the living will movement, which aimed to elicit preferences on how decisions should be made and by whom, tried to apply these standard procedures. ${ }^{5-9}$ In the process of developing validated forms, it became clear that they needed to be used as worksheets to facilitate discussions and the making of decisions. ${ }^{10}$

Moving away from the notion of a legal defense against aggressive physicians, the living will movement realized that it is the process that is the central issue. The main outcome was to honor the best available portrait of patients' desires. A good process had to do with several more things: the patients having a chance to consider and have some control over their last chapter of life, the proxy decision makers being ready for their roles, and the families having a chance to talk about issues relating to end of life and to resolve personal matters. Dying, it emerged, was a taboo topic that patients and families wanted to repossess.

But studies showed that living wills did not achieve their goal. ${ }^{11}$ Some commentators advocated dropping the whole idea. Meanwhile, the hospice movement and pal- liative care services were gaining prominence, and pioneer clinicians were trying to integrate both concepts into medical practice. ${ }^{12,13}$ Both movements accepted advance care planning as central to their philosophy of total care.

Eventually, living wills came to be seen as a vehicle for achieving greater wisdom and skill in a fundamental aspect of health care and a civilized approach to mortality. Advance care planning is a process of discussion, a component of care. Worksheets are for helping reflection and deliberation and for team building between the professionals and families and the patient. Legal documentation has a small but legitimate role. The outcomes are quality experiences for dying persons and for those caring for them. Most people facing terminal illness want to secure dignity, comfort, control, and a chance to leave a purposeful legacy. They do not want to burden their loved ones. Advance care planning with quality care at the end of life can, if done well, provide these things for most people. ${ }^{14}$

Yet, few physicians or patients initiate discussions on advance care planning. Possibly a natural ceiling exists, in that only about half of patients have estate planning wills, let alone living wills. ${ }^{15}$ But progress may be hard to measure and better than we think. The best discussions and plans for care may never be documented in a discrete, recognizable living will. Desired outcomes of peace and resolution are hard to measure and hard to compare with a suitable control group.

It is likely that most of us could improve the way we talk with, plan with, and care for patients and their families as they approach death. Validated worksheets need to be developed for different populations. Outcome measures for quality care at the end of life will need to be more sophisticated and focused on subjective, meaningful experiences of patients and families. ${ }^{16}$ Skills in breaking bad news and sharing decisions can be adapted for different cultures; skills in discerning the needs of the proxy or family and supporting them for the patient can be made suitable as well. Dying is, in the end, normal in all contexts, and the challenge is the same: can we really care for those of us who are facing our last life chapter?

Linda Emanuel is a Professor of Medicine and Director of the Interdisciplinary Program on Professionalism and Human Rights at Northwestern University.

References

1 Schiff R, Rajkumar C, Bulpitt C. Views of elderly people on living wills: interview study. BMJ 2000;320:1640-1641. 
2 Emanuel LL, Barry MJ, Stoeckle JD, Ettelson LM, Emanuel EJ. Advanced directives for medical care: a case for greater use. $N$ Engl J Med 1991;324:889-895.

3 Emanuel LL. Advance directives: evaluating their moral and empirical validity. Hastings Cent Rep 1994:24:S27-S29.

4 Nunnally JC. Psychometric Theory. 2nd ed. New York: McGraw-Hill; 1978:265-270.

5 Emanuel LL. The health care directive: learning how to draft advance care documents. J Am Geriatr Soc 1991;39:1221-1228.

6 Alpert H, Hoijtink R, Fischer G, Emanuel LL. Psychometric analysis of an advance directive. Med Care 1996;34:1055-1063.

7 Doukas DJ, Gorenflo DW. Analyzing the values history: an evaluation of patient medical values and advance directives. J Clin Ethics 1993; 4:41-45

8 Singer PA, Thiel EC, Salit I, Flanagan W, Naylor CD. The HIV-specific advance directive. J Gen Intern Med 1997;12:729-735.

9 Patrick DL, Pearlman RA, Starks HE, Cain KC, Cole WG, Uhlmann RF. Validation of preferences for life-sustaining treatment: implications for advance care planning. Ann Intern Med 1997;127:509-517.
10 EPEC Project, Institute for Ethics. Education for Physicians on End-of-Life Care (EPEC) trainer's guide. Module 1: advance care planning 1999. Available at: http://www.ama-assn.org/ethics/epec. Accessed April 26, 2000.

11 SUPPORT Principal Investigators. A controlled trial to improve care for seriously ill hospitalized patients. JAMA 1995;274:1591-1598.

12 Field MJ, Cassel CK, eds. Approaching Death: Improving Care at the End of Life. Washington, DC: National Academy Press; 1997.

13 Cassell EJ. The nature of suffering and the goals of medicine. $N$ Engl J Med 1982;306:639-645.

14 Emanuel LL. Facing requests for physician-assisted suicide: toward a practical and principled clinical skill set. JAMA 1998;280:643-647.

15 Emanuel EJ, Weinberg DS, Gonin R, Hummel LR, Emanuel LL. How well is the patient self-determination act working? an early assessment. Am J Med 1993;95:619-628.

16 Emanuel LL, Alpert H, Baldwin D, Emanuel EJ. What terminally ill patients care about: toward a validated construct of patients perspectives. J Palliat Med; in press. 